\title{
New derivatives of sulfonylhydrazone as potential antitumor agents: Design, synthesis and cheminformatics evaluation
}

\author{
DIMA A. SABBAH ${ }^{1, *}$ \\ BARA'A A. AL-AZAIDEH ${ }^{1}$ \\ WAMIDH H. TALIB ${ }^{2}$ \\ RIMA HAJJO ${ }^{1}$ \\ KAMAL SWEIDAN ${ }^{3}$ \\ AYA M. AL-ZUHEIRI \\ GHASSAN ABU SHEIKHA ${ }^{1,4}$ \\ SAWSAN SHRAIM ${ }^{1}$ \\ ${ }^{1}$ Department of Pharmacy, Faculty \\ of Pharmacy, Al-Zaytoonah University \\ of Jordan, P.O. Box 130, Amman 11733 \\ Jordan \\ ${ }^{2}$ Department of Clinical Pharmacy and \\ Therapeutics, Applied Science Private \\ University, P.O. Box 166, Amman 11931 \\ Jordan \\ ${ }^{3}$ Department of Chemistry, The University \\ of Jordan, Amman 11942, Jordan \\ ${ }^{4}$ Visiting Professor Scholar, Skaggs School \\ of Pharmacy and Pharmaceutical Science \\ University of California, San Diego, 9500 \\ Gilman Drive MC0756, La Jolla, CA \\ 92093-0756, USA
}

Accepted December 8, 2020

Published online January 15, 2021

\begin{abstract}
Phosphoinositide 3-kinase $\alpha$ (PI3K $\alpha$ ) is a propitious target for designing anticancer drugs. A series of new $N^{\prime}$ (diphenylmethylene)benzenesulfonohydrazide was synthesized and characterized using FT-IR, NMR $\left({ }^{1} \mathrm{H}\right.$ and $\left.{ }^{13} \mathrm{C}\right)$, HRMS, and elemental analysis. Target compounds exhibited an antiproliferative effect against the human colon carcinoma (HCT-116) cell line. Our cheminformatics analysis indicated that the para-tailored derivatives $\left[p-\mathrm{NO}_{2}(3)\right.$ and $\left.p-\mathrm{CF}_{3}(7)\right]$ have better ionization potentials based on calculated Moran autocorrelations and ionization potentials. Subsequent in vitro cell proliferation assays validated our cheminformatics results by providing experimental evidence that both derivatives 3 and 7 exhibited improved antiproliferative activities against HCT-116. Hence, our results emphasized the importance of electron-withdrawing groups and hydrogen bond-acceptors in the rational design of small-molecule chemical ligands targeting PI3K $\alpha$. These results agreed with the induced-fit docking against PI3K $\alpha$, highlighting the role of $p$-substituted aromatic rings in guiding the ligand-PI3K $\alpha$ complex formation, by targeting a hydrophobic pocket in the ligand-binding site and forming $\pi$-stacking interactions with a nearby tryptophan residue.
\end{abstract}

Keywords: sulfonylhydrazones, antitumor, HCT-116, PI3K $\alpha$ -inhibitors, cheminformatics, docking

Phosphatidylinositol 3-kinases (PI3Ks) are lipid kinases that incite the phosphorylation of the inositol ring of phosphatidylinositol 4,5-biphosphate $\left(\mathrm{PIP}_{2}\right)$ creating 3,4,5-triphosphate $\left(\mathrm{PIP}_{3}\right)(1,2)$. $\mathrm{PIP}_{3}$ invokes downstream signaling components like protein kinase $\mathrm{B}$ (AKT) (2). The intracellular amount of $\mathrm{PIP}_{3}$ is down-regulated by phosphatase and tensin homolog protein (PTEN) $(3,4)$. PI3Ks signaling pathway moderates cell growth, differentiation, migration, metastasis, invasion and angiogenesis (2).

Three classes of PI3Ks have been identified according to their sequences and substrates selectivity. Class IA PI3Ks harbors $\mathrm{PI} 3 \mathrm{~K} \alpha, \beta$, and $\delta$ isozymes (5). Aberrant PI3K $\alpha /$ AKT trafficking cascade has been observed in numerous human tumors (2).

\footnotetext{
*Correspondence; e-mail address: dima.sabbah@zuj.edu.jo; dima_sabbah@yahoo.com
} 
PI3K $\alpha$ gene (PIK3CA) is amplified, up-regulated and mutated in diverse human cancers (5-7). Prevalent PIK3CA mutations in the helical (E545K and E542K) and kinase (H1047R) domains are detected in colon, brain, breast and endometrial cancers (8-10). PIK3CA alterations change PI3K $\alpha$ structure and incite the in vitro kinase activity $(6,7,11$, 12).

Therefore, the design and development of selective mutant PI3K $\alpha$ inhibitor is a promising scenario for cancer treatment $(12,13)$. The high frequency of PI3K $\alpha$ and PTEN mutations shed the light on the significance of PI3K $\alpha$ as a hot target for designing and developing anticancer drugs $(14,15)$. Diverse chemical core structures have been designed and synthesized targeting PI3K $\alpha$ inhibition (16-22) and some of them have been explored in human observational studies (23-25).

Employing a pharmacophore-based drug design approach of active PI3K $\alpha$ inhibitors and screening against the National Cancer Institute (NCI) (26) database with 265,242 compounds, we identified 2-(2-hydroxy-4-methoxybenzoyl) benzoic acid (NSC 79888) as a hit (27) (Fig. 1).

Fortunately, a structural analogue of NSC 79888, 1-(diphenylmethylene) hydrazine, is available commercially and it bears the fingerprint of PI3K $\alpha$ active inhibitors (Fig. 2). Accordingly, we have hypothesized that tailoring the core structure of 1-(diphenylmethylene) hydrazine might generate potential PI3K $\alpha$ inhibitors.

Recently, we functionalized the scaffold of benzoin (NSC 8082), targeting PI3K $\alpha$ inhibition, creating 2-oxo-1,2-diphenylethyl substituted benzoates (28) and phenyl imino-1,2-diphenylethanol derivatives (21). The 2-oxo-1,2-diphenylethyl benzoate series exerted an inhibitory activity against human colon carcinoma (HCT-116) cell line with $I C_{50}$ of $0.73-2.82$ mmol L-1 and it induced apoptosis (28). However, the phenylimino-1,2-diphenylethanol derivatives exhibited selective antiproliferative activity against breast adenocarcinoma (MCF-7), breast carcinoma (T47D), and HCT-116 cell lines as well as they incited apoptosis and inhibited angiogenesis (21). Additionally, we tailored the core structure of $p$-anisoin, as a PI3K $\alpha$ inhibitor, forming a library of 1,2-bis(4-methoxyphenyl)-2-oxoethyl benzoates (22). Derivatives of 1,2-bis(4-methoxyphenyl)-2-oxoethyl benzoates showed selective suppressive activity against MCF-7, T47D and HCT-116 cell lines (22). Modeling studies displayed that the scaffold is engaged in PI3K $\alpha$ and/or ER $\alpha$ binding site. Recently, Younus et al. (29) disclosed a series of sulfonylhydrazones as potential inhibitors of ectonucleotidase (ALP \& e5'NT).<smiles>COc1ccc(C(=O)c2ccccc2C(=O)O)c(O)c1</smiles>

2-(2-Hydroxy-4-methoxybenzoyl) benzoic acid (NSC 79888)<smiles>NN=C(c1ccccc1)c1ccccc1</smiles>

1-(Diphenylmethylene) hydrazine (Diphenylmethy<smiles>[R]c1ccc(C(=O)C(O)c2ccc([R])cc2)cc1</smiles>

Benzoin (NSC 8082), $\mathrm{R}=\mathrm{H}$ p-anisoin, $\mathrm{R}=-\mathrm{OCH}_{3}$

Fig. 1. Structures of compounds 2-(2-hydroxy-4-methoxybenzoyl) benzoic acid (NSC 79888), 1-(diphenylmethylene) hydrazine, benzoin (NSC 8082) and $p$-anisoin. 
a)

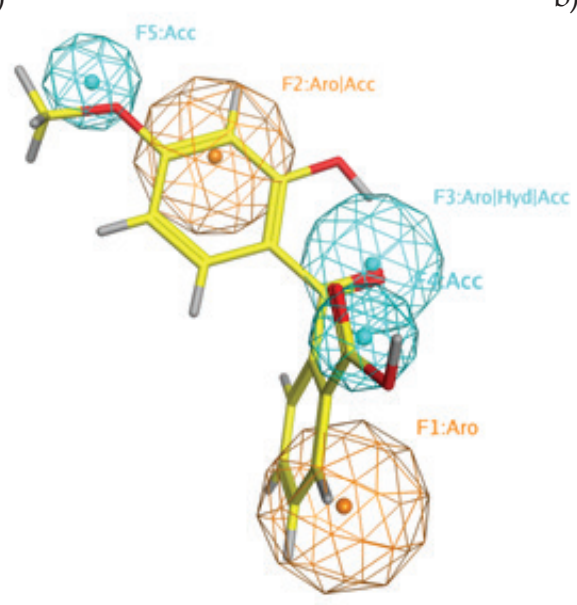

b)

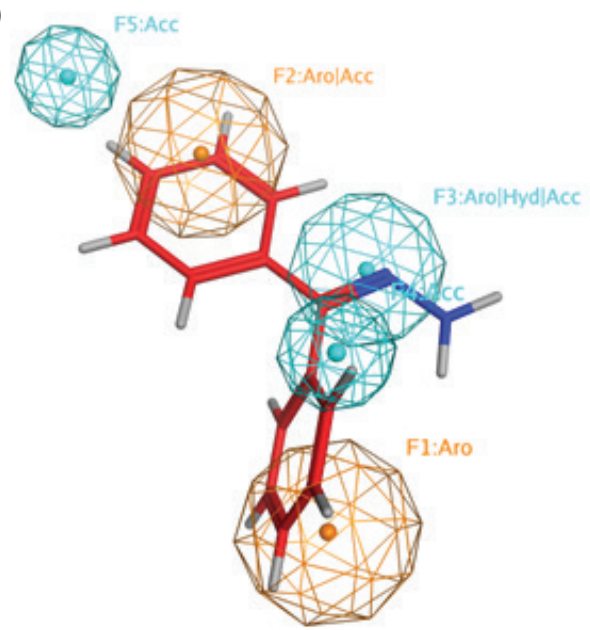

Fig. 2. Pharmacophore model of: a) NSC 79888 and b) 1-(diphenylmethylene) hydrazine. Pictures visualized by MOE (58).

In this work, we tailored the amino moiety of 1-(diphenylmethylene) hydrazine to investigate the effect of introducing benzenesulfonohydrazide motif on the occupation of PI3K $\alpha$ kinase cleft, ligand/PI3K $\alpha$ binding, and cytotoxic activity. A scaffold of $N^{\prime}$ (diphenylmethylene)-substituted benzenesulfonohydrazides was outlined to fit the pharmacophore of PI3K $\alpha$ inhibitors and exemplified in NSC 79888 (Fig. 3).

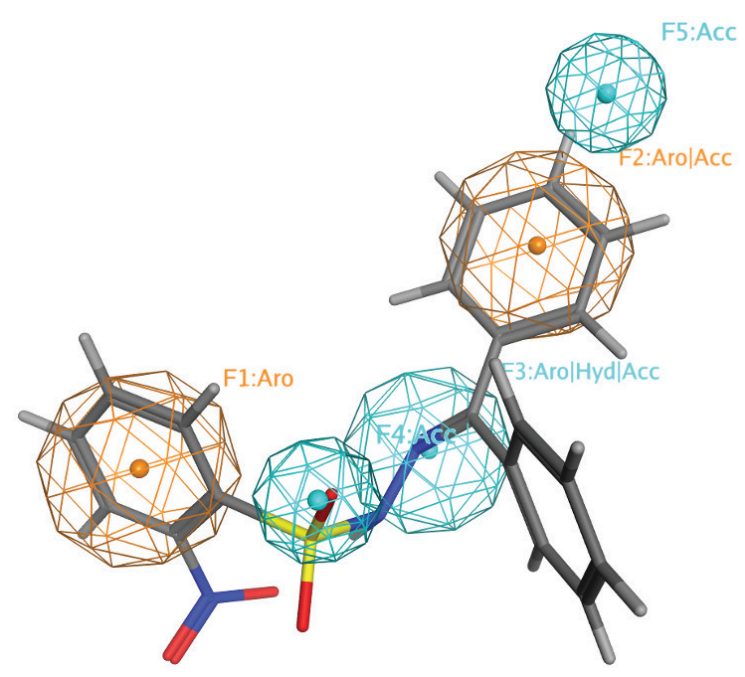

Fig. 3. Pharmacophore model with compound $\mathbf{1}$ (C atoms in grey, Aro - aromatic rings, Acc - H-bond acceptor, Hyd - hydrophobic groups). Picture captured by MOE (58). 
The derivatives were synthesized to probe the significance of attaching substituted benzenesulfonohydrazide motif to explore the structure-activity relationship (SAR) and optimize their inhibitory activity as anticancer compounds. Consequently, this work delineates the design and synthesis of $N^{\prime}$-(diphenylmethylene)-benzenesulfonohydrazides recruiting molecular docking studies. Biological evaluation of prospective compounds accompanied by non-selective PI3K inhibitor (LY294002) was examined in vitro against HCT-116 cell line.

\section{EXPERIMENTAL}

\section{Materials and equipment}

All solvents and chemicals were bought from Acros Organics (USA), Sigma-Aldrich (USA), Fluka (Switzerland), Tedia (USA), and Fisher Scientific (USA). Chemicals and solvents were manipulated as delivered and without additional purification: benzophenone hydrazone, 2-chlorobenzenesulfonyl chloride, 2-nitrobenzene sulfonyl chloride, 3-nitrobenzenesulfonyl chloride, 4-nitrobenzenesulfonyl chloride, 2-flurobenzene sulfonyl chloride, 3-flurobenzenesulfonyl chloride, and 4-trifluromethyl benzene sulfonyl chloride.

Melting points were recorded using a Gallenkamp melting point apparatus (Gemini $\mathrm{Lab}$, The Netherlands) and are uncorrected. Infrared (IR) spectra were measured as $\mathrm{KBr}$ discs using Shimadzu IR Affinity FTIR spectrophotometer (Shimadzu, Japan). ${ }^{1} \mathrm{H}$ and ${ }^{13} \mathrm{C}$ NMR spectra were documented using Bruker, Avance DPX-500 spectrometer (Bruker, USA). Chemical shifts are given in (ppm) using TMS as a reference. High-resolution mass spectra (HRMS) were acquired with the aid of a Bruker APEX-IV (7 Tesla) instrument (Bruker). External calibration was carried out by an arginine cluster at a mass range of $\mathrm{m} / \mathrm{z}$ 175-871, and the samples were got in a solution using chloroform. Elemental analyses were recorded using a EuroVector (Italy) elemental analyzer, model EUROEA3000 A.

Thin-layer chromatography (TLC) was developed on aluminum cards $(20 \times 20 \mathrm{~cm}$, layer thickness $0.2 \mathrm{~mm}$ ), pre-coated with fluorescent silica gel GF254 DC-alufolien-Kieselgel (Fluka Analytical, Germany) and visualized by UV light application at 254 and $360 \mathrm{~nm}$. The mobile phase was cyclohexane/ethyl acetate (9:1).

\section{Synthesis of $N^{\prime}$-(diphenylmethylene)-substituted benzenesulfonohydrazides (1-7)}

General procedure. - Compounds 1-7 were synthesized according to the following procedure: a mixture of benzophenone hydrazone $(1.45 \mathrm{~g}, 8 \mathrm{mmol})$ in $20 \mathrm{~mL}$ methanol was introduced to an agitated suspension of substituted benzenesulfonyl chloride (1.72 $\mathrm{g}$, 10 $\mathrm{mmol}$ ) in $40 \mathrm{~mL}$ methanol. Then, $0.5 \mathrm{~mL}$ concentrated $\mathrm{HCl}$ was added to the reaction mixture and the resulting solution was refluxed for $3 \mathrm{~h}$. The mixture was cooled to $0{ }^{\circ} \mathrm{C}$ and the residue was harvested using suction filtration, cleansed with methanol and dried under reduced pressure to collect the desired product. The obtained compounds were: $N^{\prime}$-(diphenylmethylene)-2-nitrobenzenesulfonohydrazide (1), $N^{\prime}$-(diphenylmethylene)-3-nitrobenzenesulfonohydrazide (2), $N^{\prime}$-(diphenylmethylene)-4-nitrobenzene-sulfonohydrazide (3), $N^{\prime}$-(diphenylmethylene)-2-fluorobenzenesulfonohydrazide (4), $N^{\prime}$-(diphenyl methylene)-3-fluorobenzenesulfonohydrazide (5), $N^{\prime}$-(diphenylmethylene)-2-chloroben- 
D. A. Sabbah et al:: New derivatives of sulfonylhydrazone as potential antitumor agents: Design, synthesis and cheminformatics evaluation, Acta Pharm. 71 (2021) 545-565.

Table I. Physicochemical and analytical data of the synthesized compounds 1-7

\begin{tabular}{|c|c|c|c|c|c|c|c|c|}
\hline \multirow{2}{*}{$\begin{array}{l}\text { हैं } \\
\text { हैं }\end{array}$} & \multirow{2}{*}{$\begin{array}{c}\text { Physical } \\
\text { appearance }\end{array}$} & \multirow{2}{*}{$\begin{array}{l}\text { Molecular formula } \\
\qquad\left(M_{\mathrm{r}}\right)\end{array}$} & \multirow{2}{*}{$\begin{array}{c}\text { Yield } \\
(\%)\end{array}$} & \multirow{2}{*}{$R_{f}$} & \multirow{2}{*}{$\begin{array}{l}\text { M. p. } \\
\left({ }^{\circ} \mathrm{C}\right)\end{array}$} & \multicolumn{3}{|c|}{$\begin{array}{c}\text { Analysis } \\
\text { (calcd/found) }\end{array}$} \\
\hline & & & & & & $\mathrm{C}$ & $\mathrm{H}$ & $\mathrm{N}$ \\
\hline \multirow{2}{*}{1} & \multirow{2}{*}{$\begin{array}{l}\text { Pale yellow } \\
\text { powder }\end{array}$} & $\mathrm{C}_{19} \mathrm{H}_{15} \mathrm{~N}_{3} \mathrm{O}_{4} \mathrm{~S}$ & \multirow{2}{*}{46} & \multirow{2}{*}{0.62} & \multirow{2}{*}{ 158-159 } & 59.83 & 3.96 & 11.02 \\
\hline & & (381.41) & & & & 59.46 & 4.11 & 10.86 \\
\hline \multirow{2}{*}{2} & \multirow{2}{*}{$\begin{array}{l}\text { White } \\
\text { powder }\end{array}$} & $\mathrm{C}_{19} \mathrm{H}_{15} \mathrm{~N}_{3} \mathrm{O}_{4} \mathrm{~S}$ & \multirow{2}{*}{47} & \multirow{2}{*}{0.71} & \multirow{2}{*}{ 157-158 } & 59.83 & 3.96 & 11.02 \\
\hline & & (381.41) & & & & 59.46 & 4.19 & 10.77 \\
\hline \multirow{2}{*}{3} & \multirow{2}{*}{$\begin{array}{l}\text { White } \\
\text { powder }\end{array}$} & $\mathrm{C}_{19} \mathrm{H}_{15} \mathrm{~N}_{3} \mathrm{O}_{4} \mathrm{~S}$ & \multirow{2}{*}{34} & \multirow{2}{*}{0.70} & \multirow{2}{*}{ 155-156 } & 59.83 & 3.96 & 11.02 \\
\hline & & (381.41) & & & & 60.03 & 4.23 & 11.34 \\
\hline \multirow{2}{*}{4} & \multirow{2}{*}{$\begin{array}{l}\text { Yellow } \\
\text { powder }\end{array}$} & $\mathrm{C}_{19} \mathrm{H}_{15} \mathrm{FN}_{2} \mathrm{O}_{2} \mathrm{~S}$ & \multirow{2}{*}{9} & \multirow{2}{*}{0.66} & \multirow{2}{*}{$158-159$} & 64.39 & 4.27 & 7.90 \\
\hline & & $(354.4)$ & & & & 64.02 & 4.60 & 7.67 \\
\hline \multirow{2}{*}{5} & \multirow{2}{*}{$\begin{array}{l}\text { Yellow } \\
\text { powder }\end{array}$} & $\mathrm{C}_{19} \mathrm{H}_{15} \mathrm{FN}_{2} \mathrm{O}_{2} \mathrm{~S}$ & \multirow{2}{*}{34} & \multirow{2}{*}{0.65} & \multirow{2}{*}{$156-157$} & 64.39 & 4.27 & 7.90 \\
\hline & & $(354.4)$ & & & & 64.68 & 3.95 & 8.09 \\
\hline \multirow{2}{*}{6} & \multirow{2}{*}{$\begin{array}{l}\text { Yellow } \\
\text { powder }\end{array}$} & $\mathrm{C}_{19} \mathrm{H}_{15} \mathrm{ClN}_{2} \mathrm{O}_{2} \mathrm{~S}$ & \multirow{2}{*}{32} & \multirow{2}{*}{0.63} & \multirow{2}{*}{ 153-155 } & 61.53 & 4.08 & 7.55 \\
\hline & & (370.85) & & & & 61.31 & 4.35 & 7.29 \\
\hline 7 & Yellow & $\mathrm{C}_{20} \mathrm{H}_{15} \mathrm{~F}_{3} \mathrm{~N}_{2} \mathrm{O}_{2} \mathrm{~S}$ & 38 & 0.69 & $147-149$ & 59.25 & 3.98 & 6.91 \\
\hline & powder & (404.41) & 30 & & & 58.95 & 4.15 & 7.30 \\
\hline
\end{tabular}

zene sulfono-hydrazide (6), and N'-(diphenylmethylene)-4-(trifluoromethyl)benzenesulfonohydrazide (7).

The physicochemical properties and spectral data of compounds 1-7 are given in Tables I and II.

\section{Biological testing}

In vitro cell proliferation (MTT) assay. - The antiproliferative effect of promising derivatives was detected using 3-(4,5-dimethylthiazol-2-yl)-2,5-diphenyltetrazolium bromide (MTT) test (Promega, USA). The test probes cell viability by measuring the capability of cells to reduce MTT to blue material through the activity of mitochondrial dehydrogenase (30).

Actively dividing HCT-116 cells (ATCC, Manassas, VA, USA) were generously provided by the University of Jordan (Amman, Jordan). Cells were collected, washed and dispersed in RPMI 1640 tissue culture medium. Cell viability was tested using the trypan blue staining. Cells were adhered at a density of 15,000 cells per well into 96-well tissue culture flat-bottom plates and incubated for $24 \mathrm{~h}$. Incubated cells were dissolved in DMSO and tested three times with increasing concentrations $(0.39,0.78,1.56,3.13,6.25,12.5,25$ and $50 \mathrm{mmol} \mathrm{L}^{-1}$ ) of each compound for $48 \mathrm{~h}$, and change in MTT color was measured using a microplate reader (Biotek, USA) at $595 \mathrm{~nm}$ (31). Results are presented in Table III.

Identification of VEGF expression in HCT-116 cells. - The level of VEGF in HCT-116 cells inoculated with compound 7 was assessed by VEGF enzyme-linked immunosorbent assay 


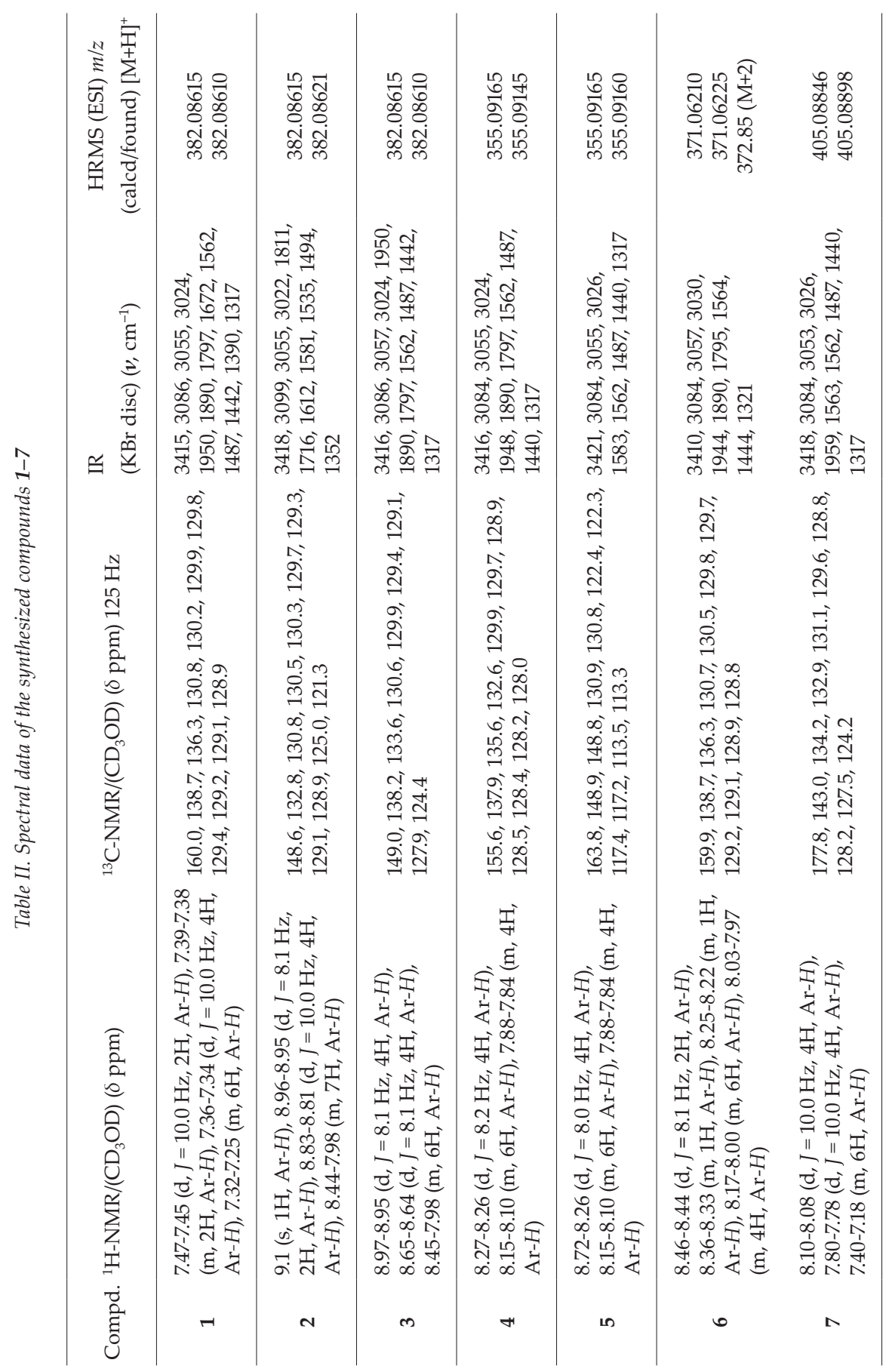


D. A. Sabbah et al.: New derivatives of sulfonylhydrazone as potential antitumor agents: Design, synthesis and cheminformatics evaluation, Acta Pharm. 71 (2021) 545-565.

Table III. PI3K $\alpha$ inhibitory activity expressed as $\mathrm{IC}_{50}$

\begin{tabular}{cc}
\hline Compd. & $I C_{50}\left(\mathrm{mmol} \mathrm{L}^{-1}\right)^{\mathrm{a}}$ \\
\hline 1 & $13.1 \pm 1.21$ \\
2 & $7.9 \pm 0.23$ \\
3 & $5.2 \pm 0.88$ \\
4 & $12.7 \pm 0.95$ \\
5 & $25.4 \pm 1.15$ \\
6 & $5.4 \pm 0.22$ \\
7 & $2.5 \pm 0.09$ \\
LY294002 & $60.0 \pm 0.09$ \\
\hline
\end{tabular}

${ }^{\mathrm{a}}$ Mean $\pm \mathrm{SEM}, n=3$.

(ELISA) kit (Sigma, USA). HCT-116 cells were prepared in small flasks at a density of $1.5 \times 10^{5}$ and subjected to one of the mentioned treatments for $48 \mathrm{~h}$ : compound $7\left(3 \mathrm{mmol} \mathrm{L}^{-1}\right)$, LY$294002\left(10 \mu \mathrm{mol} \mathrm{L}^{-1}\right)$, negative control (0.1 \% DMSO). The concentration of compound 7 was selected to be close to its $I C_{50}$ value $\left(2.5 \mathrm{mmol} \mathrm{L}^{-1}\right)$ and the concentration of LY-294002 was obtained from the previous studies on the same cell line (32). After inoculation, cells were detached using lysis buffer followed by centrifugation. Supernatants were harvested and distributed in 96-well microplates coated with anti-VEGF antibody. Biotinylated detection antibodies were added and incubated for $2.5 \mathrm{~h}$. The last step involved the addition of HRPconjugated streptavidin followed by 3,3,5,5'-tetramethylbenzidine substrate solution with 30-min treatment in dark for color development. Color intensity was measured at $450 \mathrm{~nm}$ (32).

Determination of caspase-3 activity. - The level of inducing apoptosis was detected by the caspase- 3 activity kit (Abcam, USA). HCT-116 cells were cultured as previously described and exposed to the same treatments as mentioned in the VEGF section. Caspase-3 activity was measured in treated cells following the kit protocol.

Real-time PCR. - Freshly cultured HCT-116 cells were seeded in 96-well plates at a density of 15,000 cells per well and inoculated for $48 \mathrm{~h}$ with 1-7 (3 mmol L $\left.{ }^{-1}\right)$, LY-294002 [2-(4-morpholinyl)-8-phenyl-1(4H)-benzopyran-4-one hydrochloride, $10 \mu \mathrm{mol} \mathrm{L}^{-1}$ ] and negative control ( $0.1 \%$ DMSO). Total RNA for all treatments was extracted by SV total RNA isolation system (Promega, USA) and RNA amount was quantified at 260/280 nm (Quawell NanoDrop, USA).

For cDNA synthesis, 1000 ng of RNA was applied in a $20 \mu \mathrm{L}$-reaction volume employing SCRIPT cDNA synthesis kit, Jena Bioscience (Germany). Non-specified hexamer primers were applied for reverse transcription and real-time PCR was conducted using the 5x HOT FIREPol EvaGreen qPCR Supermix, Solis BioDyne (Estonia) (33). The amplification reactions were performed using Prime Pro 48 Realtime qPCR (Techne, UK) according to the detailed reaction conditions given in Table IV. The primers displayed in Table V were used to amplify target genes and dissociation curve analysis of amplification products was created to confirm single PCR product amplification. 
D. A. Sabbah et al: New derivatives of sulfonylhydrazone as potential antitumor agents: Design, synthesis and cheminformatics evaluation, Acta Pharm. 71 (2021) 545-565.

Table IV. The qPCR standard reaction conditions

\begin{tabular}{lccc}
\hline Cycle step & Temp. $\left({ }^{\circ} \mathrm{C}\right)$ & Time $(\mathrm{s})$ & Cycles \\
\hline Initial denaturation & 95 & 720 & 1 \\
Denaturation & 95 & 15 & \\
Annealing & 62 & 25 & 40 \\
Elongation & 72 & 25 & \\
\hline
\end{tabular}

Table V. Primers used in the qPCR experiment

\begin{tabular}{ccc}
\hline Target & Forward primer $\left(5^{\prime} \rightarrow 3^{\prime}\right)$ & Reverse primer $\left(5^{\prime} \rightarrow 3^{\prime}\right)$ \\
\hline$\beta$-actin & ACGGGGTCACCCACACTGTGC & CTAGAAGCATTTGCGGTGGACGATG \\
PI3K & ACCCAGCAACAGAAAAATGG & GCGCTGTGAATTTAGCCTTC \\
AKT & AACCTGTGCTCCATGACCTC & CCCTTCTACAACCAGGACCA \\
BAD & CCTCAGGCCTATGCAAAAAG & AAACCCAAAACTTCCGATGG \\
BAX & GCTGGACATTGGAC TTCCTC & CTCAGCCCATCTTCTTCCAG \\
Bcl-2 & ATGTGTGTGGAGAGCGTCAACC & TGAGCAGAGTCTTCAGAGACAGCC \\
\hline
\end{tabular}

\section{Computational methods}

Preparation of protein ensemble. - The crystal ensemble of unbound PI3K $\alpha$ (PDB ID: 2RD0) (5) was obtained from the RCSB Protein Data Bank. The homology modeled coordinate of 2RD0 was employed for this study (34). Wortmannin template in 3HHM (35) was conveyed to 2RD0 and defined as the ligand. Energy minimization of the side-chains was employed to minimize the steric clashes by MacroModel (36) panel in MAESTRO. Additional treatment of the ensemble was accomplished by Protein preparation (36) platform in Schrödinger software to augment H-bonding between amino acids' backbones.

Preparation of ligand structures. - The prospective derivatives (ligands) were depicted using wortmannin's template in 3HHM. The ligands were drawn using MAESTRO (36) build wizard and energetically relaxed by an OPLS2005 force field in MacroModel panel.

Induced-fit docking (IFD)(36). - The co-crystallized ligand wortmannin was tagged as a centroid in the kinase domain of $2 \mathrm{RD} 0$. The van der Waals scaling factors for receptor and ligand were calibrated to 0.5 to furnish adequate relaxation for the top docked ligand conformation. Extra parameters were set as default. The ligand orientation with the most negative XP Glide score was assigned.

Cheminformatics analysis. - All molecules were treated corresponding to the protocols reported by Hajjo et al. (37). Next, 2D molecular descriptors from Kode cheminformatics (38) were generated for all seven sulfonylhydrazone derivatives described herein, plus 
PI-103 and LY-294002 as reference compounds to compare with. Molecular properties with absent constant and zero values were dropped off from the analysis.

Similarity searching. - A simple similarity searching in the STRING database (39) was conducted using the molecular structure of $\mathbf{7}$ as a query to identify 'structurally' similar compounds and identify their protein-interacting partners. STRING is a biology systems database that combines data about chemical interactions with crystal structures, genes and proteins from metabolic pathways, drug-target relationships and binding experiments. Compound 7 was represented in a SMILES format to query the STRING database. MACCS keys calculated for 7 and database compounds were compared using Tanimoto coefficients to identify similar compounds. A chemical-gene(protein) interactions search in the STRING database was performed using compound 7 and top-scoring similar hits (based on Tanimoto coefficients) as queries. All retrieved protein-protein interactions (PPIs) were used to derive a chemical-protein interactions hypothesis for compound 7.

Pathway enrichment. - Pathway enrichments were determined using a list of Bax, BAD, $\mathrm{Bcl} 2$, Akt1, PIK3 genes to query KEGG pathways (40) included in the STRING database. False discovery rates were used to prioritize and rank all enriched pathways.

\section{Data analysis}

Statistical significance was assigned using one-way analysis of variance (ANOVA) along with unpaired Student's $t$-test with significance level at $p<0.05$.

\section{RESULTS AND DISCUSSION}

\section{Chemistry}

Derivatives of $N^{\prime}$-(diphenylmethylene)-substituted benzene sulfonohydrazides (1-7) have been synthesized by treating benzophenone hydrazone with diversely substituted benzene-sulfonyl chlorides by nucleophilic substitution using methanol as polar protic

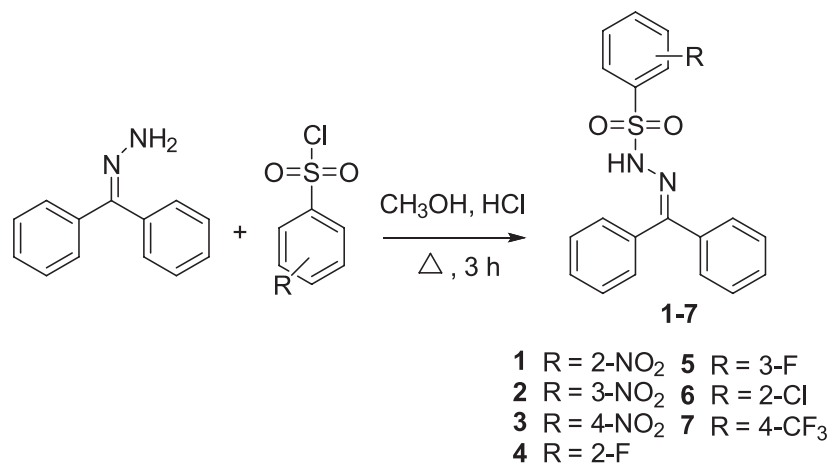

Scheme 1 
solvent under reflux for $3 \mathrm{~h}$ (Scheme 1). Substituted sulfonyl chlorides are reactive species (due to the presence of leaving group, $-\mathrm{Cl}$ ) and can be readily employed with primary amine-containing molecules to form a sulfonamide bond. The presence of electron-withdrawing groups (nitro, halogens) on the main moiety of substituted sulfonyl chlorides enhances the progress of the corresponding reaction since it may increase the electrophilicity of the sulfur atom. These groups can withdraw electrons from the phenyl ring based on the inductive effect, fluorine and chlorine atoms have higher electronegativity than carbon of the phenyl ring, while nitrogen atom in the nitro group carries a positive charge. On the other hand, the lone pair of electrons at the nitrogen atom of the hydrazone is not localized on the nitrogen atom (can be involved in resonance) and consequently decreases its nucleophilic strength. Therefore, the acid scavenger $\mathrm{HCl}$ was inserted into the reaction vessel as a catalyst and a reflux condition was applied to overcome such difficulties. Methanol was selected as a solvent since it can dissolve both reactants which permits the reaction to proceed further. Observing the reaction progression was accomplished using TLC; the absence of the spot of benzophenone hydrazone (limiting reactant) under UV light may indicate the completeness of the reaction. Retardation factor $\left(R_{f}\right)$ values of all products lied within the range of $0.62-0.71$; in general, the $R_{\mathrm{f}}$ value between $0.3-0.8$ is required for routine TLC experiments since it indicates that the organic material is relatively pure and no two spots or more do overlap each other. Constitutional isomers of the nitro group (1-3) show closer $R_{\mathrm{f}}$ values which may be attributed to the relatively large size of the final products, which, consequently, minimizes the effect of different positions of the nitro group.

The identity of the synthesized compounds has been confirmed using various techniques such as: NMR, HRMS, IR and elemental analysis (Table II). These data are in accord with the defined structures. Concerning NMR data, all signals are observed in the range of the aromatic region (6.5-8.5 ppm) for ${ }^{1} \mathrm{H}$ NMR and from $120-150 \mathrm{ppm}$ for ${ }^{13} \mathrm{C}$ NMR; values of coupling constants $(J)$ are within expected ranges for ortho-protons $(8-10 \mathrm{~Hz})$. The signal of $\mathrm{N}-\mathrm{H}$ was not observed in ${ }^{1} \mathrm{H}$ NMR spectra due to the rapid proton exchange with $\mathrm{CD}_{3} \mathrm{OD}$. The chemical shift of carbon of $\mathrm{C}=\mathrm{N}$ is resonated at about $155 \mathrm{ppm}$ in the target products. It is clear that there are no significant differences in chemical shifts of each proton and carbon among constitutional isomers of products that have a nitro group (1-3) or fluorine atom (4-5).

Furthermore, the mass spectra of verified derivatives confirm the precise molecular ion peaks for which the measured high resolution (HRMS) data are in agreement with the calculated values, based on the positive mode (by adding one extra hydrogen atom). Products that contain two nitrogen atoms (4-7) showed even molar masses while those with three nitrogen atoms (1-3) exhibited odd molar masses in the consistency to the nitrogen rule. Compound 6 shows two main peaks $\left(\mathrm{M}^{+}\right.$and $\left.\mathrm{M}+2^{+}\right)$and this is due to the presence of the chlorine atom (isotope effect); this trend was not observed when fluorine was present in compounds 4,5 and 7 . No peaks for the fragmentation ions were detected in the employed high-resolution mass spectrometer.

Regarding IR data, no two IR bands were detected at about $3400 \mathrm{~cm}^{-1}$ which indicates that no primary amino group is present in the target products $1-7$, instead, one band is observed in that region which belongs to $\mathrm{N}-\mathrm{H}$ functional group. It is interesting to note that the absence of such two synchronous IR bands assures that benzophenone hydrazone (reactant) is not present in the products. In addition, the IR band of the $\mathrm{C}=\mathrm{N}$ group is 
observed at about $1560 \mathrm{~cm}^{-1}$. The presence of phenyl rings in the products (1-7) is clear in IR data due to the presence of IR bands at $1440-1560 \mathrm{~cm}^{-1}$. Derivatives of sulfonyl chloride (reactants) usually exhibit two synchronous strong bands at about 1490 and $1190 \mathrm{~cm}^{-1}$ but no such bands were observed in IR spectra of products 1-7.

Elemental analyses (Table I) assure the purity of the target products in which calculated and experimental values for $\mathrm{C}, \mathrm{H}, \mathrm{N}$ are within the accepted ranges. Carbon content in the target products is high and ranged from about $58-64 \%$; this is expected due to the presence of three phenyl rings. It is worth noting that each sample should be well dried prior to the analysis to avoid any error in the measurements, in particular, for hydrogen element (low content $\sim 4 \%$ ).

\section{Biological activity}

Screening against human colon carcinoma (HCT-116) cell line demonstrated that compounds 1-7 exhibited a suppressive action encoding PI3K $\alpha$ (Table III).

The malignant human colon carcinoma cell line (HCT-116) expresses the wild-type (WT) and mutant (MUT) (H1047R) PI3K $\alpha$ and it was generated from an original tumor through biological procedures (41). Our results uncovered promising antiproliferative activities of designed compounds 3 and 7 bearing $p-\mathrm{NO}_{2}$ and $p-\mathrm{CF}_{3}$ moieties consequently. Further analysis revealed that the presence of electron-withdrawing groups or hydrogen bond-acceptors on the $p$-position affects the electrostatic properties of the aromatic ring required for guiding ligand-PI3K $\alpha$ interactions in the binding pocket. On the contrary, the inhibitory activity of $o-\mathrm{Cl}(\mathbf{6})$ indicates that hydrophobic force guides ligand/PI3K $\alpha$ engagement. Additionally, the antiproliferative activity of $o-\mathrm{NO}_{2}(\mathbf{1})$ and $o-\mathrm{F}(4)$ confirms that the hydrophobic pocket encloses the $o$-substituent. Contrasting the activity of $m-\mathrm{NO}_{2}(2)$ to that of $m$-F (5) clarifies that $\mathrm{NO}_{2}$ might occupy properly the binding cleft. Though, both motifs provide $\mathrm{H}$-bond interaction; the steric effect improves the binding affinity.

Further biological testing of the most active compound (7) revealed its potential as an angiogenesis inhibiting agent. Angiogenesis is an essential process for cancer survival; vascular endothelial growth factor (VEGF) is one of the main proteins that start the angiogenesis process (33). Treating HCT-116 cells with 7 at a concentration of $3 \mathrm{mmol} \mathrm{L}^{-1}$ generated a significant $(p<0.05)$ reduction in the levels of VEGF $v s$. the negative control $(0.1 \%$ DMSO) (Fig. 4). Our results agree with reported studies that demonstrated a decrease in VEGF level after treating cells with PI3K/AKT/mTOR pathway inhibitors (42). Apoptosis (programmed cell death) induction is a complex process involving activation and inhibition of different mediator molecules. Caspases are among these mediators and their activation stimulates the process of apoptosis and cell death (43). In our study, compound 7 generated a considerable increase in caspase-3 activity compared with the negative control. A similar increase was also noticed in cells inoculated with the positive control (LY-294002) (Fig. 5).

Moreover, the qPCR technique was accomplished to test the effect of 7 on genes' expression involved in the apoptosis process. Treating cells with $7\left(3 \mathrm{mmol} \mathrm{L}^{-1}\right)$ caused a decrease in the expression levels of PI3K and AKT (Fig. 6). Also, it induced the pre-apoptotic genes' encryption (BAX and BAD) and inhibited anti-apoptotic gene (BCL2) expression. 
a)

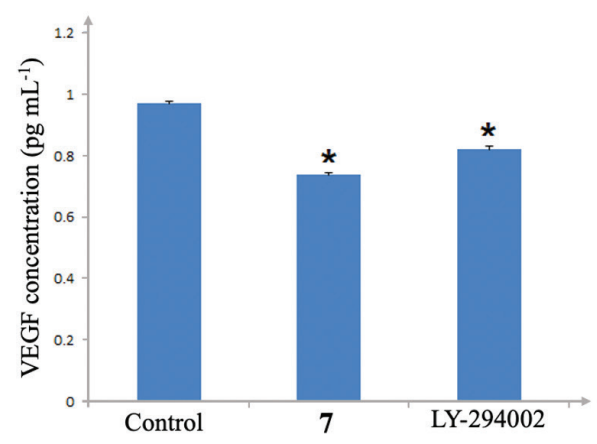

b)

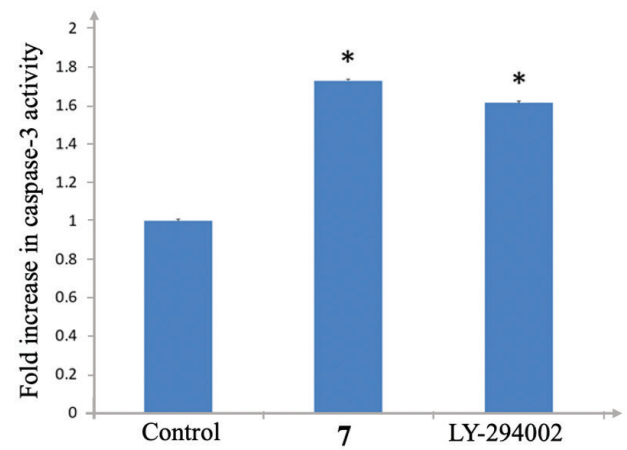

Fig. 4. The evaluation of antitumor effects of tested compounds after inoculation with compound 7 (3 mmol L-1), LY-294002 [2-(4-morpholinyl)-8-phenyl-1(4H)-benzopyran-4-one hydrochloride, $10 \mu \mathrm{mol}$ $\mathrm{L}^{-1}$ ), and negative control. a) Vascular endothelial growth factor (VEGF) in HCT-116 cells, b) caspase-3 activity in HCT-116 cells (folds increase was calculated by dividing caspase-3 activity of the treatment by the activity of the negative control). Results represented as mean $\pm \operatorname{SEM}(n=3)$. Significant difference compared with the control: ${ }^{*} p<0.05$.

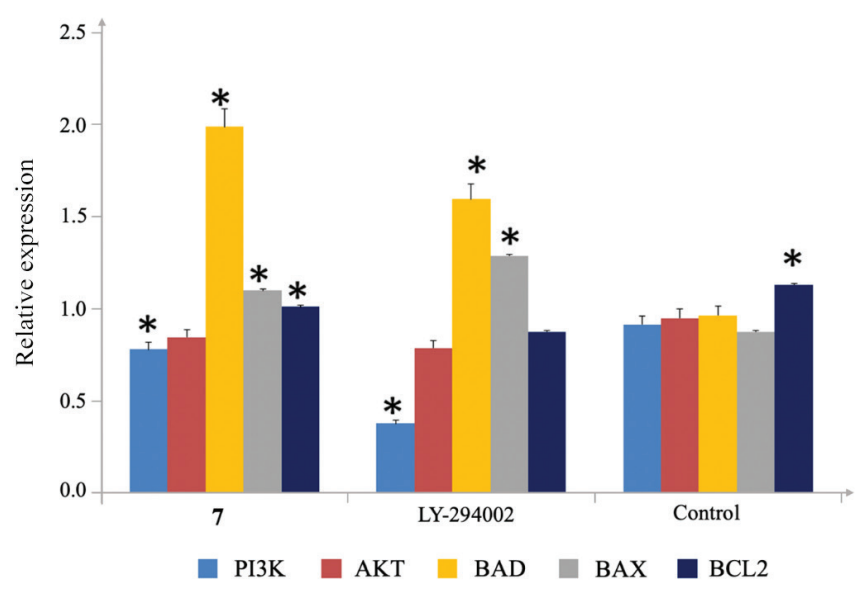

Fig. 5. Relative RNA expression of target genes in HCT-116 cells inoculated with compound 7 ( 3 mmol $\left.\mathrm{L}^{-1}\right)$, LY-294002 [2-(4-morpholinyl)-8-phenyl-1(4H)-benzopyran-4-one hydrochloride, $\left.10 \mu \mathrm{mol} \mathrm{L}^{-1}\right)$, for $48 \mathrm{~h}$, and negative control. Results are represented as mean $\pm \operatorname{SEM}(n=3)$. Significant difference compared with the control: ${ }^{*} p<0.05$.

\section{Computational studies}

To identify the anticancer activity of the compounds 1-7 in the human colon carcinoma (HCT-116) cell line, we recruited the coordinates of PI3K $\alpha$ (PDB ID: 2RD0) (5) to explore the binding interaction of this series of compounds in PI3K $\alpha$ binding site. 2RD0 binding site 


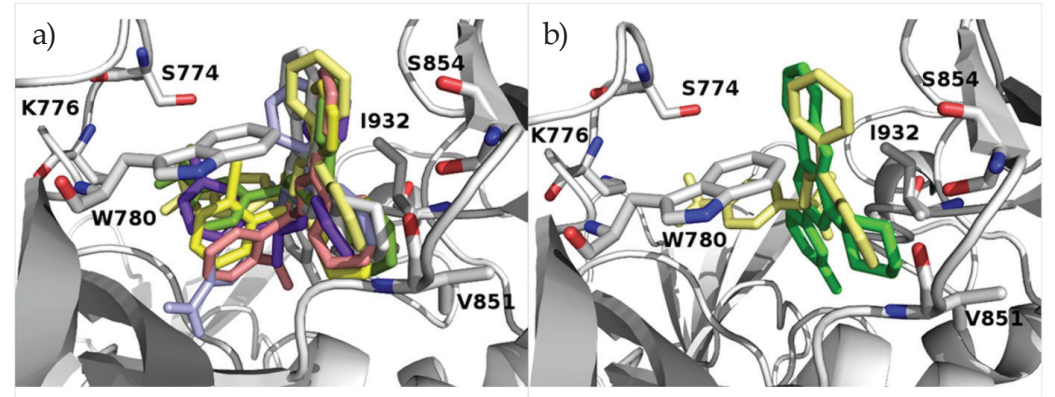

c)

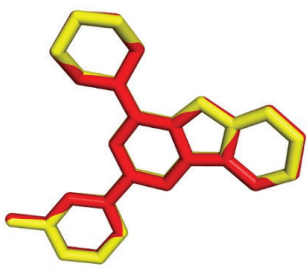

d)

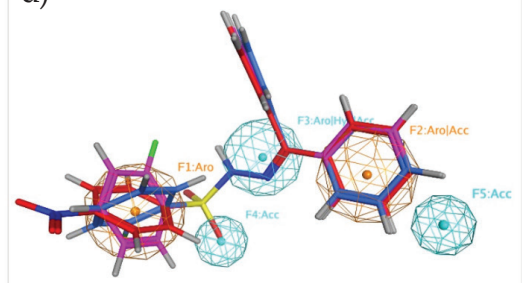

Fig. 6. Molecular modeling using docking and pharmacophore models. The kinase site: a) 2RD0 accommodates the IF docked poses of 1-7 and b) superposition of the IF docked conformation of 7 (depicted in yellow color) and the bound ligand (wortmannin) (green color). Some of the significant binding amino acids are shown and $\mathrm{H}$ atoms are unseen for clarity purpose. Picture visualized by PYMOL.c) The IFD X6K orientation and its original geometry in 4L23. The native template is sketched in red color and the docked pose is yellow-colored. Picture visualized by PYMOL. d) PI3K $\alpha$ inhibitors' pharmacophore model with $\mathbf{1}$ (blue color), $\mathbf{3}$ (red color) and $\mathbf{6}$ (pink color).

harbors Met772, Lys776, Trp780, Ile800, Lys802, Leu807, Asp810, Tyr836, Ile848, Glu849, Val850, Val851, Ser854, Thr856, Gln859, Met922, Phe930, Ile932, and Asp933. The polar and hydrophobic linings occupy the kinase cleft. Additionally, the surface area (polar and nonpolar) of the bound ligand accords with nearby residues. The polar backbones furnish dipole-dipole, ion-dipole and H-bonding. The polar basic or acidic amino acids provide an electrostatic (ionic) bonding. The non-polar backbone like hydrophobic and aromatic residue mediates hydrophobic (van der Waals) and aromatic ( $\pi$-stacking) engagement, resp.

To generate a highly accurate ligand-protein complex structure we performed an induced fit docking (IFD) study against the kinase domain of PI3K $\alpha$ using PDB structure 2RD0. The generated model was then used to predict the binding poses of ligands 1-7, postulating the structural basis for ligand-PI3K $\alpha$ interactions. Our IFD results demonstrate that 1-7 occupy the PI3K $\alpha$ kinase cleft (Fig. 6a). Actually, the docked pose of 7 overlays that of the bound ligand conformation (Fig. 6b). The IFD approach probes the geometry changes in proteins in particular; ligands are oriented to PI3K $\alpha$ binding site recruiting Glide docking $(36,44,45)$ and the highest ligand geometries are minimized along with protein binding site employing the Prime wizard (36). Then, a re-docking protocol is recruited against the relaxed coordinates.

The backbones of the synthesized molecules engage with the backbones of Ser774 and Lys802 through H-bond (Table VI and Supplementary Figs. S1-S3). It's worth noting that 


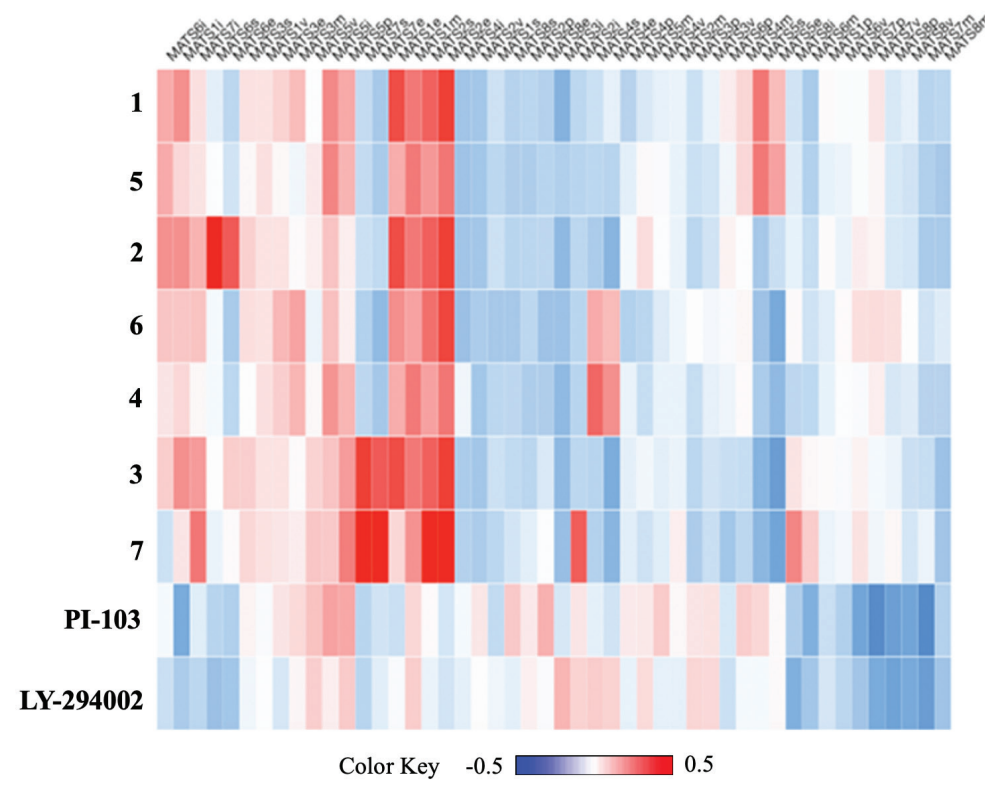

Fig. 7. Heatmap visualization of the hierarchical clustering results of synthesized compounds and known PI3K $\alpha$ inhibitors using Euclidean distances and complete linkages. Matrix red/blue cells stand for positive/negative values, resp.

hydrophobic (van der Waals) and aromatic ( $\pi$-stacking) bonding predominates ligand/ PI3K $\alpha$ complex formation. Actually, other computational $(20,28,34,46)$ and investigational studies (5) underlined the significance of these amino acids in ligand engagement.

Table VI. IFD scores and H-bonding

\begin{tabular}{ccc}
\hline Compd. & $\begin{array}{c}\text { IF-docking score } \\
\left(\text { kcal mol }^{-1}\right)\end{array}$ & Binding residue(s) \\
\hline $\mathbf{6 a}$ & -8.75 & K802 \\
$\mathbf{6 b}$ & -8.11 & S774 \\
$\mathbf{6 c}$ & -8.52 & $\mathrm{NA}$ \\
$\mathbf{6 d}$ & -7.82 & $\mathrm{NA}$ \\
$\mathbf{6 e}$ & -8.36 & $\mathrm{NA}$ \\
$\mathbf{6 f}$ & -8.37 & $\mathrm{NA}$ \\
$\mathbf{6 g}$ & -6.84 & $\mathrm{NA}$ \\
LY294002 & -9.79 & Y836, V851, D933 \\
\hline
\end{tabular}

LY294002 - 2-(4-morpholinyl)-8-phenyl-1(4H)-benzopyran-4-one hydrochloride; NA - not available 
a)<smiles>CC(C)(C)c1ccc(NNC(=O)c2ccccc2)cc1</smiles>

Query

7

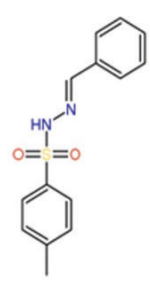

Hit 1 $\mathrm{Tc}=0.77$<smiles>Cc1ccc(S(=O)(=O)N/N=C\c2c(F)c(F)c(F)c(F)c2F)cc1</smiles>

Hit 2<smiles>O=S1(=O)NC=Cc2ccccc21</smiles>

Hit 3

b)

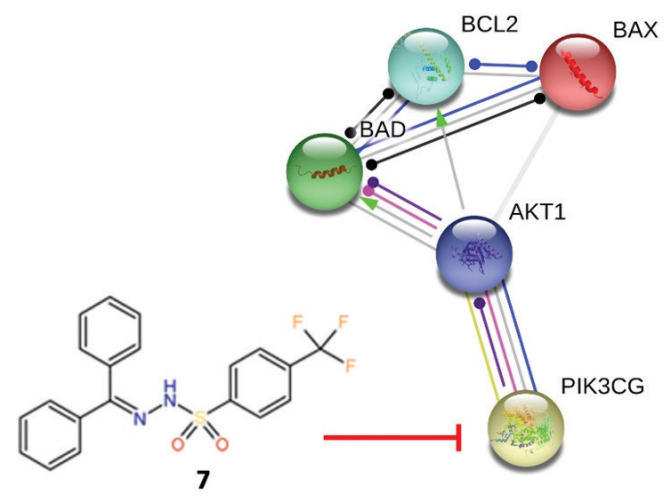

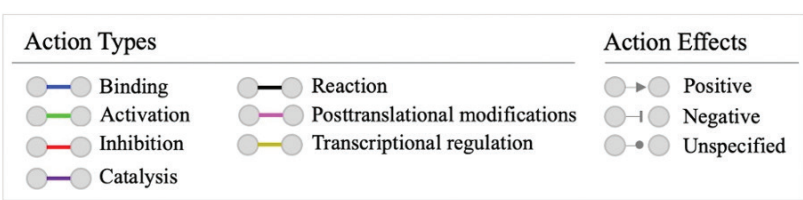

Fig. 8. Similarity searching and network analysis. a) Top three scoring chemical hits obtained from similarity searching in STRING database using Tanimoto coefficient (Tc) (50) as a distance metric and compound 7 as a query. b) A schematic presentation of the proposed network of functional interactions between compund 7, PI3K, AKT1, BAD, BCL2 and BAX.

The docking study shows that 1-7 exhibited comparable binding energy in the PI3K $\alpha$ kinase site. The binding scores against PI3K $\alpha$ predict that this scaffold might be a possible PI3K $\alpha$ inhibitor. The more negative the binding scores of 1-7 against PI3K $\alpha$ anticipate that this series might exert an encouraging inhibitory activity against PI3K $\alpha$. Very small negative docking scores of $\mathbf{1 - 7}$, against PI3K $\alpha$, suggest that these compounds are promising putative inhibitors for this enzyme.

To assess the accomplishment of the IFD program, we contrasted the docked geometry of X6K in PI3K $\alpha$ (PDB ID: 4L23) (47) to its original orientation in the crystal structure. Fig. $6 \mathrm{c}$ showed the overlaying of the IFD-produced $\mathrm{X} 6 \mathrm{~K}$ geometry and the original orientation 
in 4L23. The heavy atoms (all atoms except H) RMSD of X6K between the IFD-produced docked pose and the original pose was $0.126 \AA$. This declares that IFD is able to generate the original pose in the crystal coordinates and can consistently anticipate the ligand interaction geometry.

In order to investigate the tailored functionalities of $1-7$, we mapped them against a reported pharmacophore model of active PI3K $\alpha$ inhibitors (27). The backbone of 1-7 fit the structural features of active PI3K $\alpha$ inhibitors (Fig. 6d), represented as F1 indicating one aromatic ring, F2 H-bond acceptor or one aromatic ring; F3 H-bond acceptor or one aromatic ring or hydrophobic motif, and each (F4) or (F5) one H-bond acceptor. This finding rationalizes the propensity of the dataset against PI3K $\alpha$ kinase cleft. Furthermore, the accommodation of 1-7 in the kinase domain provides an explanation for their PI3K $\alpha$ antiproliferative activity.

Cheminformatics analysis of the seven sulfonylhydrazone compounds in addition to two known PI3K $\alpha$ inhibitors LY-294002 (non-selective PI3K $\alpha$ inhibitor) and PI-103 (selective PI3K $\alpha$ inhibitor) was performed to determine whether our compounds have diverse drug-like properties and if there are any similar compounds published in public chemogenomics databases. Analysis results indicated that our compounds differ in their drug-likeness based on Alva 2D drug-like indices and Euclidean indices. Compounds $\mathbf{6}$ and 7 have distinct drug-like properties from the rest of the synthesized benzenesulfonohydrazide compounds (Fig. 7). Results also showed that that PI-103 and LY-294002 have drug-like properties distant from our synthesized compounds.

In order to understand the meaning of these differences in drug-likeness, we evaluated correlated Alva's drug-like indices that showed variation across synthesized compounds. This analysis revealed that there is a great correlation between drug-like indices such as Neoplastic-80, Inflammat-80 and Hypertens-80, indicating that the introduced structural changes on benzenesulfonohydrazide derivatives have comparable effects on calculated (i.e., predicted) drug-like properties, which predicts that our compounds might have anti-inflammatory and antihypertensive properties.

Additionally, a thorough analysis of 330 2D Alva descriptors that showed variation in their values between synthesized compounds, highlighted MATS descriptors (Moran autocorrelation) as possible contributors for these drug-like differences between synthesized compounds.

Three descriptors belonging to Moran autocorrelations weighted by ionization potentials, namely MATS2i, MATS6i, and MATS8i differentiated between compound 7 ( $p$ - $\mathrm{CF}_{3}$ derivative), and to a lower extent between compound 3 ( $p-\mathrm{NO}_{2}$ derivative), and the rest of sulfonylhydrazone analogs. These findings were validated experimentally in biological assays where the $p-\mathrm{CF}_{3}(7)$ and the $p-\mathrm{NO}_{2}$ (3) showed improved growth inhibition of the HCT-116 cell line. These results confirmed that unique molecular ionization properties of the $p-\mathrm{NO}_{2}(6 \mathrm{c})$ and $p-\mathrm{CF}_{3}(7)$ compounds, reflected in three calculated MATS descriptors mentioned above, conferred improved growth inhibition behavior in the HTC-116 cancer cell line. We also found evidence in the biomedical literature showing that ionization sites in drug molecules determine the $\mathrm{pK}$ a values of these drugs at specific $\mathrm{pH}$, and consequently, the resulting $\mathrm{p} K_{\mathrm{a}}$ values of the drugs will influence many properties, including dissolution rate, solubility, formulation, reaction kinetics, cell permeability, receptor interactions, and protein binding (48).

Similarity searching in the STRING database was performed using 2D circular fingerprints FCFP (49) as molecular descriptors and Tanimoto coefficient (Tc) (50) as a distance 
metric. Results indicated that the top three most similar structural hits to 7 in the STRING database, i.e., compounds that have the highest Tc values, based on the presence or absence of molecular fingerprints that represent 7 , are: $N^{\prime}$-benzylidene- $p$-toluene-sulfonohydrazide (Tc -0.77$)$, pentafluorobenzaldehyde tosylhydrazone $(\mathrm{Tc}-0.66)$ and benzothiadiazine dioxide (Tc - 0.65) (Fig. 8a). This analysis also showed that compound 7 has a unique descriptor profile for MATS6i, MATS2i and MATS8i but the rest of the pheynylhydrazone analogs. However, the only hit that had annotated protein connections in STRING is the benzothiadiazine dioxide (Tc - 0.65). There is evidence in the biomedical literature that benzothiadiazine-1,1-dioxides are promising therapeutic options for human malignancies $(50,51)$ and human cytomegalovirus (HCMV) infections (52). Some derivatives are positive allosteric modulators of AMPA receptors (53) and others are considered ionotropic glutamate receptor ligands.

Pathway enrichment results using genes regulated by our compounds as query genes (Fig. 8b) led to the prioritization of several important biological pathways that might contribute in the process of antiproliferative activity of our lead compound 7 (supplementary tables SI and SII). Solid tumor pathways such as pancreatic cancer, prostate cancer, gastric cancer, colorectal cancer, hepatocellular and endometrial cancer, were among the top 20 most statistically significant pathways, indicating that our compounds could be valuable anticancer agents for solid tumors. All enriched pathways were sorted according to their false discovery rates (FDRs) calculated using the Benjamini and Hochberg method (55), to correct the enrichment $p$-values for multiple testing. All $p$-values were calculated using the hypergeometric test (56). All details about STRING interaction networks can be found in ref. 57 .

\section{CONCLUSIONS}

The phosphatidylinositol 3-kinase (PI3K $\alpha$ ) has been promoted as a hot receptor for the antitumor drug design. In this work, a new series of $N^{\prime}$-(diphenyl methylene) benzene sulfonohydrazides was designed and developed as promising PI3K $\alpha$ inhibitors. Biological investigation in the HCT-116 cell line displayed that the series inhibits PI3K $\alpha$ activity. Cheminformatics analyses showed that the $p$-tailored analogues $\left[p-\mathrm{NO}_{2}(3)\right.$ and $\left.p-\mathrm{CF}_{3}(7)\right]$ have better ionization potentials than the rest of synthesized molecules $(\mathbf{1}, \mathbf{2}, \mathbf{4}, \mathbf{5}$ and $\mathbf{6})$ expressed by calculated Moran autocorrelations. Derivative incorporating $o$-motif (6) demonstrates that a hydrophobic interaction includes ligand/PI3K $\alpha$ engagement. Bioactivity of $m$-attachment (2) deduces that a steric effect improves the binding interaction. The induced-fit docking strategies against the PI3K $\alpha$ kinase site showed that the derivatives form H-bond with Ser774 and Lys802.

Acronyms, abbreviations, symbols. - AKT - protein kinase B, MTT - 3-(4,5-dimethylthiazol2-yl)-2,5-diphenyltetrazolium bromide, MUT - mutant, PI3Ks - phosphatidylinositol 3-kinases, $\mathrm{PIP}_{2}$ - phosphatidylinositol-4,5-biphosphate, PTEN - phosphatase and tensin homolog protein, VEGF vascular endothelial growth factor, WT - wild-type.

Acknowledgments. - This work was financially contributed by Al-Zaytoonah University of Jordan Deanship of Scientific Research and Graduate Studies (Grant number: 2018-2017/28/16). We thank the University of Jordan, the Chemistry Department for spectroscopic analysis. We are grateful to the College of Pharmacy, the Applied Science University for use molecular biology laboratory and tools.

Supplementary material. - Additional figures and tables are embedded in the supporting file and available upon request. 
D. A. Sabbah et al:: New derivatives of sulfonylhydrazone as potential antitumor agents: Design, synthesis and cheminformatics evaluation, Acta Pharm. 71 (2021) 545-565.

\section{REFERENCES}

1. B. Vanhaesebroeck, L. Stephens and P. Hawkins, PI3K signalling: the path to discovery and understanding, Nat. Rev. Mol. Cell Biol. 13 (2012) 195-203; https://doi.org/10.1038/nrm3290

2. I. Vivanco and C. L. Sawyers, The phosphatidylinositol 3-kinase-AKT pathway in human cancer, Nat. Rev. Cancer 2 (2002) 489-501; https://doi.org/10.1038/mrc839

3. B. Vanhaesebroeck and M. D. Waterfield, Signaling by distinct classes of phosphoinositide 3-kinases, Exp. Cell Res. 253 (1999) 239-254; https://doi.org/10.1006/excr.1999.4701

4. L. C. Cantley, The phosphoinositide 3-kinase pathway, Science 296 (2002) 1655-1657; https://doi. org/10.1126/science.296.5573.1655

5. C.-H. Huang, D. Mandelker, O. Schmidt-Kittler, Y. Samuels, V. E. Velculescu, K. W. Kinzler, B. Vogelstein, S. B. Gabelli and L. M. Amzel, The structure of a human p110 alpha/p85 alpha complex elucidates the effects of oncogenic PI3K alpha mutations, Science 318 (2007) 1744-1748; https://doi. org/10.1126/science.1150799

6. N. Miled, Y. Yan, W.-C. Hon, O. Perisic, M. Zvelebil, Y. Inbar, D. Schneidman-Duhovny, H. J. Wolfson, J. M. Backer and R. L. Williams, Mechanism of two classes of cancer mutations in the phosphoinositide 3-kinase catalytic subunit, Science 317 (2007) 239-242; https://doi.org/10.1126/science.1135394

7. L. Zhao and P. K. Vogt, Helical domain and kinase domain mutations in p110 alpha of phosphatidylinositol 3-kinase induce gain of function by different mechanisms, Proc. Natl. Acad. Sci. USA. 105 (2008) 2652-2657; https://doi.org/10.1073/pnas.0712169105

8. Y. Samuels and V. E. Velculescu, Oncogenic mutations of PIK3CA in human cancers, Cell Cycle 3 (2004) 1221-1224; https://doi.org/10.4161/cc.3.https://doi.org/10.1164

9. Y. Samuels, L. A. Diaz, O. Schmidt-Kittler, J. M. Cummins, L. DeLong, I. Cheong, C. Rago, D. L. Huso, C. Lengauer, K. W. Kinzler, B. Vogelstein and V. E. Velculescu, Mutant PIK3CA promotes cell growth and invasion of human cancer cells, Cancer Cell 7 (2005) 561-573; https://doi. org/10.1016/j.ccr.2005.05.014.

10. P. Liu, H. Cheng, S. Santiago, M. Raeder, F. Zhang, A. Isabella, J. Yang, D. J. Semaan, C. Chen, E. A. Fox, N. S. Gray, J. Monahan, R. Schlegel, R. Beroukhim, G. B. Mills and J. J. Zhao, Oncogenic PIK3CA-driven mammary tumors frequently recur via PI3K pathway-dependent and PI3K pathway-independent mechanisms, Nat. Med. 17 (2011) 1116-1120; https://doi.org/10.1038/nm.2402

11. L. Zhao and P. K. Vogt, Hot-spot mutations in p110 $\alpha$ of phosphatidylinositol 3-kinase (PI3K): differential interactions with the regulatory subunit p85 and with RAS, Cell Cycle 9 (2010) 596-600; https://doi.org/10.4161/cc.9.3.10599

12. P. Liu, H. Cheng, T. M. Roberts and J. J. Zhao, Targeting the phosphoinositide 3-kinase pathway in cancer, Nat. Rev. Drug Discov. 8 (2009) 627-644; https://doi.org/10.1038/nrd2926

13. T. M. Bauer, M. R. Patel and J. R. Infante, Targeting PI3 kinase in cancer, Pharmacol. Ther. 146 (2015) 53-60; https://doi.org/10.1016/j.pharmthera.2014.09.006

14. M. Cully, H. You, A. J. Levine and T. W. Mak, Beyond PTEN mutations: the PI3K pathway as an integrator of multiple inputs during tumorigenesis, Nat. Rev. Cancer 6 (2006) 184-192; https://doi. org/10.1038/nrc1819

15. A. Carracedo and P. P. Pandolfi, The PTEN-PI3K pathway: of feedbacks and cross-talks, Oncogene 27 (2008) 5527-5541; https://doi.org/10.1038/onc.2008.247

16. M. Hayakawa, H. Kaizawa, H. Moritomo, T. Koizumi, T. Ohishi, M. Okada, M. Ohta, S.-I. Tsukamoto, P. Parker, P. Workman and M. Waterfield, Synthesis and biological evaluation of 4-morpholino-2-phenylquinazolines and related derivatives as novel PI3 kinase p110 alpha inhibitors, Bioorg. Med. Chem. 14 (2006) 6847-6858; https://doi.org/10.1016/j.bmc.2006.06.046 
D. A. Sabbah et al:: New derivatives of sulfonylhydrazone as potential antitumor agents: Design, synthesis and cheminformatics evaluation, Acta Pharm. 71 (2021) 545-565.

17. M. Hayakawa, H. Kaizawa, K.-I. Kawaguchi, N. Ishikawa, T. Koizumi, T. Ohishi, M. Yamano, M. Okada, M. Ohta, S.-I. Tsukamoto, F. I. Raynaud, M. D. Waterfield, P. Parker and P. Workman, Synthesis and biological evaluation of imidazo[1,2-a]pyridine derivatives as novel PI3 kinase p110 alpha inhibitors, Bioorg. Med. Chem. 15 (2007) 403-412; https://doi.org/10.1016/j.bmc.2006.09.047

18. M. Hayakawa, H. Kaizawa, H. Moritomo, T. Koizumi, T. Ohishi, M. Yamano, M. Okada, M. Ohta, S. Tsukamoto, F. I. Raynaud, P. Workman, M. D. Waterfield and P. Parker, Synthesis and biological evaluation of pyrido[3',2':4,5]furo[3,2-d]pyrimidine derivatives as novel PI3 kinase p110alpha inhibitors, Bioorg. Med. Chem. Lett. 17 (2007) 2438-2442; https://doi.org/10.1016/j.bmcl.2007.02.032

19. D. A. Sabbah, N. A. Simms, W. Wang, Y. Dong, E. L. Ezell, M. G. Brattain, J. L. Vennerstrom and H. A. Zhong, N-phenyl-4-hydroxy-2-quinolone-3-carboxamides as selective inhibitors of mutant H1047R phosphoinositide-3-kinase (PI3K $\alpha)$, Bioorg. Med. Chem. 20 (2012) 7175-7183; https://doi. org/10.1016/j.bmc.2012.09.059

20. D. A. Sabbah, B. Hishmah, K. Sweidan, S. Bardaweel, M. AlDamen, H. A. Zhong, R. Abu Khalaf, I. Hasan, T. Al-Qirim and G. Abu Sheikha, Structure-based design: Synthesis, X-ray crystallography, and biological evaluation of N-substituted-4-hydroxy-2-quinolone-3-carboxamides as potential cytotoxic agents, Anticancer Agents Med. Chem. 18 (2018) 263-276; https://doi.org/10.2174/18715 20617666170911171152

21. D. A. Sabbah, F. Al-Tarawneh, W. H. Talib, K. Sweidan, S. K. Bardaweel, E. Al-Shalabi, H. A. Zhong, G. Abu Sheikha, R. Abu Khalaf and M. S. Mubarak, Benzoin Schiff bases: Design, synthesis, and biological evaluation as potential antitumor agents, Med. Chem. 14 (2018) 695-708; https:// doi.org/10.2174/1573406414666180412160142

22. D. A. Sabbah, A. H. Ibrahim, W. H. Talib, K. M. Alqaisi, K. Sweidan, S. K. Bardaweel, G. A. Sheikha, H. A. Zhong, E. Al-Shalabi and R. A. Khalaf, Ligand-based drug design: Synthesis and biological evaluation of substituted benzoin derivatives as potential antitumor agents, Med. Chem. 15 (2019) 417-429; https://doi.org/10.2174/1573406414666180912111846

23. D. Kong and T. Yamori, Advances in development of phosphatidylinositol 3-kinase inhibitors, Curr. Top. Med. Chem. 16 (2009) 2839-2854; https://doi.org/10.2174/092986709788803222

24. D. A. Sabbah, M. G. Brattain and H. A. Zhong, Dual inhibitors of PI3K/mTOR or mTOR-selective inhibitors: Which way shall we go?, Curr. Med. Chem. 18 (2011) 5528-5544; https://doi. org/10.2174/092986711798347298

25. D. A. Sabbah, J. Hu and H. A. Zhong, Advances in the development of class I phosphoinositide 3-kinase (PI3K), Curr. Top. Med. Chem. 16 (2016) 1413-1426; https://doi.org/10.2174/156802661566615 0915115823

26. National Institutes of Health, National Cancer Institute, NCI Open Database Compounds, Release 4, NCI, Bethesda (MD) 2012; http://cactus.nci.nih.gov/download/nci, last access date June 15, 2017

27. D. A. Sabbah, N. A. Simms, M. G. Brattain, J. L. Vennerstrom and H. Zhong, Biological evaluation and docking studies of recently identified inhibitors of phosphoinositide-3-kinases, Bioorg. Med. Chem. Lett. 22 (2012) 876-880; https://doi.org/10.1016/j.bmcl.2011.12.044

28. D. A. Sabbah, M. Saada, R. A. Khalaf, S. Bardaweel, K. Sweidan, T. Al-Qirim, A. Al-Zughier, H. A. Halim and G. A. Sheikha, Molecular modeling based approach, synthesis, and cytotoxic activity of novel benzoin derivatives targeting phosphoinostide 3-kinase (PI3K $\alpha$ ), Bioorg. Med. Chem. Lett. 25 (2015) 3120-3124; http://dx.doi.org/https://doi.org/10.1016/j.bmcl.2015.06.011

29. H. A. Younus, A. Hameed, A. Mahmood, M. S. Khan, M. Saeed, F. Batool, A. Asari, H. Mohamad, J. Pelletier, J. Sévigny, J. Iqbal and M. al-Rashida, Sulfonylhydrazones: Design, synthesis and investigation of ectonucleotidase (ALP \& e5'NT) inhibition activities, Bioorg. Chem. 100 (2020) Article ID 103827; https://doi.org/https://doi.org/10.1016/j.bioorg.2020.103827

30. W. H. Talib and A. M. Mahasneh, Antiproliferative activity of plant extracts used against cancer in traditional medicine, Sci. Pharm. 78 (2010) 33-46; https://doi.org/10.3797/scipharm.0912-11 
D. A. Sabbah et al:: New derivatives of sulfonylhydrazone as potential antitumor agents: Design, synthesis and cheminformatics evaluation, Acta Pharm. 71 (2021) 545-565.

31. W. H. Talib, Consumption of garlic and lemon aqueous extracts combination reduces tumor burden by angiogenesis inhibition, apoptosis induction, and immune system modulation, Nutr. J. 43-44 (2017) 89-97; https://doi.org/https://doi.org/10.1016/j.nut.2017.06.015

32. W. H. Talib, Regressions of breast carcinoma syngraft following treatment with piperine in combination with thymoquinone, Sci. Pharm. 85 (2017) 27-38; https://doi.org/10.3390/scipharm85030027

33. W. H. Talib and L. T. Al Kury, Parthenolide inhibits tumor-promoting effects of nicotine in lung cancer by inducing P53 - dependent apoptosis and inhibiting VEGF expression, Biomed. Pharmacother. 107 (2018) 1488-1495; https://doi.org/10.1016/j.biopha.2018.08.139

34. D. A. Sabbah, J. L. Vennerstrom and H. Zhong, Docking studies on isoform-specific inhibition of phosphoinositide-3-kinases, J. Chem. Inf. Model. 50 (2010) 1887-1898; https://doi.org/https://doi. org/10.1021/ci1002679

35. D. Mandelker, S. B. Gabelli, O. Schmidt-Kittler, J. Zhu, I. Cheong, C.-H. Huang, K. W. Kinzler, B. Vogelstein and L. M. Amzel, A frequent kinase domain mutation that changes the interaction between PI3K alpha and the membrane, Proc. Natl. Acad. Sci. USA 106 (2009) 16996-7001; https:// doi.org/10.1073/pnas.0908444106

36. Protein Preparation Wizard, Maestro, Macromodel, and QPLD-dock, Schrödinger, LLC, Portland, (OR), 2016

37. R. Hajjo, C. M. Grulke, A. Golbraikh, V. Setola, X.-P. Huang, B. L. Roth and A. Tropsha, Development, Validation, and use of quantitative structure-activity relationship models of 5-hydroxytryptamine (2B) receptor ligands to identify novel receptor binders and putative valvulopathic compounds among common drugs, J. Med. Chem. 53 (2010) 7573-7586; https://doi.org/10.1021/ jm100600y

38. Alvascience, alvaDesc (software for molecular descriptors calculation) version 1.0.18, 2020, Lecco, Italy; https://www.alvascience.com

39. D. Szklarczyk, J. H. Morris, H. Cook, M. Kuhn, S. Wyder, M. Simonovic, A. Santos, N. T. Doncheva, A. Roth, P. Bork, L. J. Jensen and C. von Mering, The STRING database in 2017: quality-controlled protein-protein association networks, made broadly accessible, Nucleic Acids Res. 45 (2016) D362D368; https://doi.org/10.1093/nar/gkw937

40. M. Kanehisa, M. Araki, S. Goto, M. Hattori, M. Hirakawa, M. Itoh, T. Katayama, S. Kawashima, S. Okuda, T. Tokimatsu and Y. Yamanishi, KEGG for linking genomes to life and the environment, Nucleic Acids Res. 36 (2007) D480-D484; https://doi.org/10.1093/nar/gkm882

41. M. G. Brattain, A. E. Levine, S. Chakrabarty, L. C. Yeoman, J. K. V. Willson and B. Long, Heterogeneity of human colon carcinoma, Cancer Metastasis Rev. 3 (1984) 177-191; https://doi.org/10.1007/ bf00048384

42. J. Karar and A. Maity, PI3K/AKT/mTOR pathway in angiogenesis, Front. Mol. Neurosci. 4 (2011) Article ID 51; https://doi.org/10.3389/fnmol.2011.00051

43. W. H. Talib, S. A. Al-Hadid, M. B. W. Ali, I. H. Al-Yasari and M. R. A. Ali, Role of curcumin in regulating p53 in breast cancer: an overview of the mechanism of action, Breast Cancer (Dove Med Press) 10 (2018) 207-217; https://doi.org/10.2147/bctt.s167812

44. R. A. Friesner, J. L. Banks, R. B. Murphy, T. A. Halgren, J. J. Klicic, D. T. Mainz, M. P. Repasky, E. H. Knoll, M. Shelley, J. K. Perry, D. E. Shaw, P. Francis, P. S. Shenkin, Glide: A new approach for rapid, accurate docking and scoring. 1. Method and assessment of docking accuracy, J. Med. Chem. 47 (2004) 1739-1749; https://doi.org/10.1021/jm0306430

45. R. A. Friesner, R. B. Murphy, M. P. Repasky, L. L. Frye, J. R. Greenwood, T. A. Halgren, P. C. Sanschagrin, D. T. Mainz, Extra precision glide: Docking and scoring incorporating a model of hydrophobic enclosure for protein-ligand complexes, J. Med. Chem. 49 (2006) 6177-6196; https://doi. org/10.1021/jm051256o 
46. K. Sweidan, D. A. Sabbah, S. Bardaweel, K. A. Dush, G. A. Sheikha, M. S. Mubarak, Computer-aided design, synthesis, and biological evaluation of new indole-2-carboxamide derivatives as PI3K $\alpha$ /EGFR inhibitors, Bioorg. Med. Chem. Lett. 26 (2016) 2685-2690; https://doi.org/10.1016/j. bmcl.2016.04.011

47. Y. Zhao, X. Zhang, Y. Chen, S. Lu, Y. Peng, X. Wang, C. Guo, A. Zhou, J. Zhang, Y. Luo, Q. Shen, J. Ding, L. Meng and J. Zhang, Crystal structures of PI3K $\alpha$ complexed with PI103 and its derivatives: new directions for inhibitors design, ACS Med. Chem. Lett. 5 (2014) 138-142; https://doi.org/10.1021/ m1400378e

48. D. J. Adams and L. R. Morgan, Tumor physiology and charge dynamics of anticancer drugs: implications for camptothecin-based drug development, Curr. Med. Chem. 18 (2011) 1367-1372; https:// doi.org/10.2174/092986711795029609

49. J. W. Godden, L. Xue and J. Bajorath, Combinatorial preferences affect molecular similarity/diversity calculations using binary fingerprints and Tanimoto coefficients, J. Chem. Inf. Comput. Sci. 40 (2000) 163-166; https://doi.org/10.1021/ci990316u

50. A. Kamal, S. Azeeza, E. V. Bharathi, M. S. Malik and R. V. Shetti, Search for new and novel chemotherapeutics for the treatment of human malignancies, Mini Rev. Med. Chem. 10 (2010) 405-435; https://doi.org/10.2174/138955710791330918

51. A. Kamal, Y. V. V. Srikanth, M. Ashraf, M. N. A. Khan, T. B. Shaik, S. V. Kalivendi, N. Suri and A. K. Saxena, Synthesis and anticancer activities of new benzothiadiazinyl hydrazinecarboxamides and anilino[1,2,4]triazolo[1,5-b][1,2,4]thiadiazine 5,5-diones, Med. Chem. 7 (2011) 165-172; https:// doi.org/10.2174/157340611795564259

52. A. Martinez, C. Gil, A. Castro, A. M. Bruno, C. Pérez, C. Prieto and J. Otero, Benzothiadiazine dioxide human cytomegalovirus inhibitors: synthesis and antiviral evaluation of main heterocycle modified derivatives, Antivir. Chem. Chemother. 14 (2003) 107-114; https://doi. org/10.1177/095632020301400206

53. E. Goffin, T. Drapier, A. P. Larsen, P. Geubelle, C. P. Ptak, S. Laulumaa, K. Rovinskaja, J. Gilissen, P. de Tullio, L. Olsen, K. Frydenvang, B. Pirotte, J. Hanson, R. E. Oswald, J. S. Kastrup and P. Francotte, 7-Phenoxy-substituted 3,4-dihydro-2H-1,2,4-benzothiadiazine 1,1-dioxides as positive allosteric modulators of $\alpha$-amino-3-hydroxy-5-methyl-4-isoxazolepropionic acid (AMPA) receptors with nanomolar potency, J. Med. Chem. 61 (2018) 251-264; https://doi.org/10.1021/acs. jmedchem.7b01323

54. The Molecular Operating, Environment Chemical Computing Group, Inc., Montreal (Quebec) Canada, 2016 